\title{
ASSESSMENT OF THE STRENGTH REDUCTION FACTOR IN PREDICTING THE FLEXURAL STRENGTH
}

\author{
Sema Alacali, Guray Arslan \\ Yildiz Technical University, Department of Civil Engineering, Istanbul, Turkey \\ e-mail: semanoyal@gmail.com; aguray@yildiz.edu.tr
}

\begin{abstract}
In the design of flexural strength, the strength reduction factor $\phi$ decreases from tension-controlled sections to compression-controlled sections to increase safety with decreasing ductility. This paper presents how to determine the reduction factor for flexural strength of reinforced concrete beams according to ACI code. In the reliability-based design, the reliable prediction of the flexural strength of reinforced concrete members is assured by the use of reduction factors corresponding to different target reliability index $\beta$. In this study, for different $\beta$ and coefficients of variation of the flexural strength parameters, the flexural strength reduction factor has been investigated by using experimental studies available in the literature. In the reliability analysis part of the study, the first-order second moment approach (FOSM) has been used to determine the reduction factor. It has also been assumed that the random variables are statistically independent.
\end{abstract}

Keywords: reinforced concrete, beam, flexure strength, reduction factor, target reliability

\section{Introduction}

In the design of flexural strength, tension-controlled sections are desirable for their ductile behavior for giving sufficient warning prior to failure. Hence, reinforced concrete (RC) elements are designed to behave in a ductile manner, whenever possible. This behavior can be ensured by limiting the amount of reinforcement such that tension reinforcement yields prior to concrete crushing. In ACI 318 codes $(1995,1999,2002,2005,2008,2011,2014)$, a lower strength reduction $(\phi)$ factor is used for compression-controlled sections compared to the one for tension-controlled sections because the compression-controlled sections are less ductile. Naaman (2004) noted that changes made from the ACI 318 (1999) to the ACI 318 (2002) codes relocated the limits for tension and compression controlled sections and added a transition region between the two. The flaw lies in this definition for these regional boundaries.

In the codes, it is intended to provide the target failure probability by means of safety factors that are load factors and strength reduction factors (Arslan et al., 2017). Safety factors depend on the selected target reliability index $\beta$, which is established in terms of the acceptable probability of failure varying with the considered loading condition, type of failure mode and material (Arslan et al., 2016). According to Du and Au (2005), the reliability indexes based on the requirements of the strength limit state for bridge girders are 3.9-4.4, 5.2-5.3 and 3.4-3.5 according to AASHTO (1998), the Chinese Code (1991) and the Hong Kong Code (2002), respectively. Nowak et al. (2001) compared the reliability levels of prestressed concrete girders designed using Spanish Code (1998), Eurocode ENV 1991-3 (1994), and AASHTO (1998), and indicated that the reliability indexes varied considerably for the three codes. The reliability indexes for bridge girders were 7.0-8.0, 5.1-6.8 and 4.5-4.9 according to Eurocode ENV 1991-3 (1994), the Spanish Code (1998) and AASHTO (1998), respectively. In this study, the change in the strength reduction factor considered in predicting the flexural strength of tension-controlled 
sections according to ACI 318 (2014) is investigated and compared for different reliability indexes and coefficients of variation of the flexural strength parameters.

\section{Design of RC beams for flexure}

According to ACI 318 (2014), the nominal flexural strength $M_{n}$ of a beam section is computed from internal forces at the ultimate strain profile when the extreme compressive fiber strain is equal to 0.003. Sections in flexure exhibit different modes of failure depending on the strain level in the extreme tension reinforcement. According to Section 21.2 of ACI 318 (2014), these modes are defined as tension-controlled sections, compression-controlled sections and a transition region between the tension- and compression-controlled sections. Tension-controlled sections have the net tensile strain in the extreme tension steel either equal to or greater than 0.005. Compression-controlled sections have the net tensile strain in the extreme tension reinforcement either equal to or less than the compression-controlled strain limit when the concrete in compression reaches the strain limit of 0.003. The compression-controlled strain limit is the net tensile strain in the reinforcement at balanced strain conditions. Compression-controlled sections have strains equal to or less than the yield strain, which is equal to 0.002 for Grade 420 reinforcement. There exists a transition region between the tension- and compression-controlled sections.

The nominal flexural strength of a rectangular section with tension reinforcement is computed from the internal force couple for tension failure by the yielding of the reinforcement. The nominal flexural strength of the beams $M_{n}$ can be calculated as

$$
M_{n}=A_{s} f_{y} d-0.59 \frac{A_{s}^{2} f_{y}^{2}}{b f_{c}}
$$

in which $A_{s}$ is the area of the flexural reinforcement, $f_{y}$ is the yield strength of the reinforcement, $f_{c}$ is the compressive strength of concrete, $d$ and $b$ are the effective depth and beam width, respectively.

The governing equation given by ACI 318 (2014) states that the reduced (design) strength $\phi M_{n}$ must exceed the ultimate (factored) moment $M_{u}$, and the safety criteria for flexural design of the $\mathrm{RC}$ beams can be defined as

$$
\phi M_{n} \geqslant M_{u}
$$

in which $\phi$ is the strength reduction factor for flexure. According to ACI 318 (2014), the $\phi$ for an element depends on parameters such as the ductility and the importance of the element in terms of the reliability of the entire structure. For tension-controlled sections, a $\phi$ of 0.90 is used. Compression-controlled sections are defined as having strain limit at the nominal strength at or below the yield strain of the reinforcement. For compression-controlled sections, the $\phi$ is either 0.65 or 0.75 depending on the nature of the lateral confinement reinforcement. For sections with reinforcement strains between the aforementioned two limits, the strength reduction factor $\phi$ is determined by a linear interpolation between the value of $\phi$ for tension- and compression-controlled sections.

\section{Reliability analysis}

In reliability analysis, the main objective of engineering planning and design is to insure the performance of an engineering system. Under conditions of uncertainty, the assurance of the performance is possible with the use of safety factors. The reliability assessment requires knowledge of the performance function to define the safety factors (Ang and Tang, 1984). The performance 
function, $Z=g\left(X_{1}, X_{2}, \ldots, X_{n}\right)$, can be determined in terms of many random variables as load components, resistance parameters, material properties. In this equation, $X_{i}$ are basic random variables influencing the limit state. The failure surface can be defined as $Z=0$. The safety or reliability is defined by $Z>0$, and the failure state is $Z<0$. In the reliability based design, the problem is to determine the partial safety factors of the variables according to the target reliability index $\beta$. In this study, the first-order second moment approach (FOSM) is used and the design points $\gamma_{i} m_{X_{i}}$ corresponding to the target reliability index $\beta$ are obtained. In the space of reduced variates, $\beta$ being a measure of reliability is defined as the shortest distance from the failure surface to the origin.

The limit state function can be defined with Eq. (3.1) by multiplying the safety factor $\gamma_{i}$ with each of the basic design variables

$$
g\left(\gamma_{1} m_{X_{1}}, \gamma_{2} m_{X_{2}}, \ldots, \gamma_{i} m_{X_{i}}\right)=0 \quad i=1,2, \ldots, n
$$

$x_{i}^{*}\left(=\gamma_{i} m_{X_{i}}\right)$ is the most probable failure point on the failure surface, and the determination of $x_{i}^{*}$ requires an iterative solution. In the space of reduced variates, the most probable failure point is $x_{i}^{\prime *}=-\alpha_{i}^{*} \beta$. The sensitivity coefficient $\alpha_{i}^{*}$ is defined by

$$
\alpha_{i}^{*}=\frac{\partial g}{\partial X_{i}^{\prime}} / \sqrt{\sum_{i=1}^{n}\left(\frac{\partial g}{\partial X_{i}^{\prime}}\right)_{*}^{2}}
$$

The partial safety factors required for the given $\beta$ are defined as $\gamma_{i}\left(=x_{i}^{*} / m_{X_{i}}\right)$. The original variates are given by $x_{i}^{*}=m_{X_{i}}\left(1-\alpha_{i}^{*} \beta V_{X_{i}}\right)$, in which $m_{X_{i}}$ and $V_{X_{i}}$ are the mean value and the variance coefficient of the original variable $X_{i}$ with normal distribution, respectively. $V_{X_{i}}$ is the ratio of standard deviation $\sigma_{X_{i}}$ to the mean value $m_{X_{i}}$. The partial safety factors are calculated as (Nowak and Collins, 2000)

$$
\gamma_{i}=1-\alpha_{i}^{*} \beta V_{X_{i}}
$$

In this study, the distributions of random variables in the performance function are given in Table 1. In lognormal and extreme type I distributions, $m_{X_{i}}$ and $\sigma_{X_{i}}$ are replaced by the equivalent normal mean $m_{X_{i}}^{N}$ and standard deviation $\sigma_{X_{i}}^{N}$. In addition, it is also assumed that the random variables are statistically independent.

\subsection{Establishment of performance function}

According to ACI 318 (2014), the strength reduction factor for flexure ranges from 0.70 to 0.90 depending on the nature of the lateral confinement reinforcement and the strain level in the extreme tension reinforcement. The reduction factors for $\mathrm{RC}$ beams have been investigated by considering the reliability indexes $\beta(5.2,4.75,4.27,3.72,3.5,3.09$ and 2.33) corresponding to various failure probabilities $p_{F}\left(10^{-7}, 10^{-6}, 10^{-5}, 10^{-4}, 2.33 \cdot 10^{-4}, 10^{-3}\right.$ and $\left.10^{-2}\right)$. The performance function used in the calculations is given by

$$
g(X)=\gamma_{1} M_{n}-\gamma_{2} M_{u}
$$

in which $M_{u}$ is the ultimate (factored) moment at the RC beam section that can be taken as the test result and $M_{n}$ is the nominal flexural strength of the beam defined in ACI 318 (2014). $\gamma_{1}$ and $\gamma_{2}$ are the strength reduction factors for the corresponding variables. 


\subsection{Coefficients of variation of design parameters}

The ultimate (factored) and nominal flexural strength of the beams obtained through experiments and equation have been modeled as random variables to perform a probability-based analysis. In modeling of those parameters as random variables, the values of coefficients of variations have been determined based on the studies available in the literature and codes. They are summarized in Table 1. In the literature review (Table 1), it has been observed that the coefficient of variation of the concrete compressive strength $V_{f_{c}}$ varies between 0.10 and 0.21 , depending on the construction quality (Arslan et al., 2015). By taking advantage of studies in the literature and codes, it is assumed that $V_{f_{c}}$ is $0.05,0.10$ and 0.15 , respectively, in this study.

Table 1. Coefficients of variation of the variables

\begin{tabular}{|c|c|c|c|c|c|c|}
\hline \multirow{2}{*}{ Cases } & \multicolumn{6}{|c|}{ Coefficients of variation } \\
\hline & $f_{y}$ & $f_{c}$ & $A_{s}$ & $b$ & $d$ & $M_{u}$ \\
\hline$\overline{\text { Case } 1}$ & \multirow{3}{*}{0.03} & $\overline{0.05}$ & \multirow{12}{*}{0.04} & \multirow{12}{*}{0.03} & \multirow{12}{*}{0.03} & \multirow{12}{*}{0.04} \\
\hline Case 2 & & 0.10 & & & & \\
\hline Case 3 & & 0.15 & & & & \\
\hline Case 4 & \multirow{3}{*}{0.05} & 0.05 & & & & \\
\hline Case 5 & & 0.10 & & & & \\
\hline Case 6 & & 0.15 & & & & \\
\hline Case 7 & \multirow{3}{*}{0.07} & 0.05 & & & & \\
\hline Case 8 & & 0.10 & & & & \\
\hline Case 9 & & 0.15 & & & & \\
\hline Case 10 & \multirow{3}{*}{0.10} & 0.05 & & & & \\
\hline Case 11 & & 0.10 & & & & \\
\hline Case 12 & & 0.15 & & & & \\
\hline $\begin{array}{c}\text { Distribution } \\
\text { type }\end{array}$ & $\begin{array}{c}\text { Log- } \\
\text {-normal }\end{array}$ & $\begin{array}{c}\text { Log- } \\
\text {-normal }\end{array}$ & Normal & Normal & Normal & $\begin{array}{c}\text { Extreme } \\
\text { type I }\end{array}$ \\
\hline
\end{tabular}

The coefficient of variation of the reinforcement yield strength $V_{f_{y}}$ has also been reported by many researchers, and $V_{f_{y}}$ ranges from 0.05 to 0.15 (Arslan et al., 2016). $V_{f_{y}}$ was taken as 0.03 by Nowak et al. (2005), 0.05 by JCSS (2000), 0.06 by Soares et al. (2002), 0.07 by Akiyama et al. (2012), 0.08 by Val et al. (1997), Hosseinnezhad et al. (2000) and Low and Hao (2001), 0.08-0.11 by Ostlund (1991), 0.12 by Enright and Frangopol (1998), 0.15 by Mirza (1996). In the present study, model variations of $f_{y}$ are taken as 0.03, 0.05, 0.07 and 0.10 , respectively.

The coefficients of variation of the effective depth $V_{d}$, width $V_{b}$ and tensile reinforcement area $V_{A_{s}}$ of beams have also been reported by many researchers. $V_{d}$ was taken as 0.02 by $\mathrm{Lu}$ et al. (1994), 0.03 by Wieghaus and Atadero (2011), 0.04 by Nowak and Szerszen (2003) and Szerszen et al. (2005). $V_{b}$ was taken as 0.04 by Nowak and Szerszen (2003) and Szerszen et al. (2005). It is assumed that the $V_{d}, V_{b}$ and $V_{A_{s}}$ are $0.03,0.03$ and 0.04 , respectively, in this study.

To carry out the reliability analysis of RC beam specimens, a meaningful probability distribution for the nominal flexural strength parameters and ultimate flexural strength is also necessary. In the present study, randomness of the applied load is described using Extreme type I distribution. In the studies by Hognestad (1951) and Mirza (1996), it was assumed that the coefficient of variation of strength due to test procedure was 0.04 , which is the value used in this study.

\subsection{Properties of beams}

In the determination of the flexural strength reduction factors, 84 beams with flexural failure collected from 3 different researches (Johnson and Cox, 1939; Ashour, 2000; Pam et al., 2001) 
have been evaluated. The number of beams produced from normal-strength concrete (NSC) and high-strength concrete (HSC) with $f_{c} \geqslant 55 \mathrm{MPa}$ are 52 and 32, respectively. The beams have a broad range of design parameters: $22.0 \leqslant f_{c} \leqslant 48.6 \mathrm{MPa}, 0.17 \leqslant \rho \leqslant 2.37 \%, 200 \leqslant b \leqslant 305 \mathrm{~mm}$ and $215 \leqslant d \leqslant 305 \mathrm{~mm}$ for NSC beams and $57.1 \leqslant f_{c} \leqslant 107.1 \mathrm{MPa}, 1.03 \leqslant \rho \leqslant 4.04 \%$, $120 \leqslant b \leqslant 200 \mathrm{~mm}$ and $208 \leqslant d \leqslant 260 \mathrm{~mm}$ for HSC beams.

\section{Investigating the strength reduction}

The ACI 318 code imposes a $\phi$ factor of 0.65 when the strain in the tension reinforcement equals 0.002 for Grade 420 reinforcement. The $\phi$ increases linearly to the maximum value of 0.90 as the tension strain increases from 0.002 to 0.005 . A tension-controlled section is defined as a cross section in which the tensile strain in the extreme tension reinforcement at the nominal strength is greater than or equal to 0.005 . Tension-controlled sections are desirable for their ductile behavior, which allows redistribution of the stresses and sufficient warning against an imminent failure. It is always a good practice to design $\mathrm{RC}$ elements to behave in a ductile manner, whenever possible. For tension-controlled sections, a $\phi$ factor of 0.9 has been used.

In the design of RC beams, to apply a higher resistance factor $\phi$ of 0.9 , the member should exhibit desirable behavior. In this study, $\phi$ factors of the ACI 318 code are investigated for tension-controlled beam sections. For different $V_{f_{c}}$ and $V_{f_{y}}$, the value of $\phi$ corresponding to $\beta$ $\left(2.33,3.09,3.50,3.72,4.27,4.75\right.$ and 5.20) and different $V_{f_{c}}$ and $V_{f_{y}}$ are summarized for NSC, HSC and all beams (NSC and HSC) in Table 2. For a given $\beta$ and different $V_{f_{c}}$ and $V_{f_{y}}$, the value of $\phi$ for HSC beams is found to be smaller than the one for NSC beams, so it can be inferred that $\phi$ for NSC beams is more safe than that for HSC beams.

Saatcioglu (2014) indicated that the ACI 318 (2005) adopted strength reduction factors that were compatible with ASCE7-02 (2002) load combinations, except for the tension controlled section for which the $\phi$ was increased from 0.80 to 0.90 .

In this study, it is founded that 0.80 value of $\phi$ corresponds to the target values of $\beta=3.5$, $V_{f_{c}}=0.05$ and $V_{f_{y}}=0.10$ in all analyzed beams. In ACI 318 (2014), $\phi$ considered in predicting flexural strength of beams is updated as 0.90 , which corresponds to the target values of $\beta=3.5$, $V_{f_{y}}=0.05$ and $V_{f_{c}}=0.05$, in all analyzed beams. It is observed that this value is conservative for $\beta$ in the range from 2.33 to 5.20 for $V_{f_{y}}=0.05$ and $V_{f_{c}} \leqslant 0.15$ in NSC beams, and it can also be noted that it is conservative for $\beta$ in the range from 2.33 to 5.20 for $V_{f_{y}}=0.03$ and $V_{f_{c}} \leqslant 0.15$ in HSC beams.

The values of $\phi$ obtained from the analyses which have been performed by considering different $V_{f_{c}}(0.05,0.10$ and 0.15$), V_{f_{y}}(0.03,0.05,0.07$ and 0.10$)$ and $\beta(5.2,4.75,4.27,3.72,3.50$, 3.09 and 2.33) values of the beam sections are shown in Fig. 1.
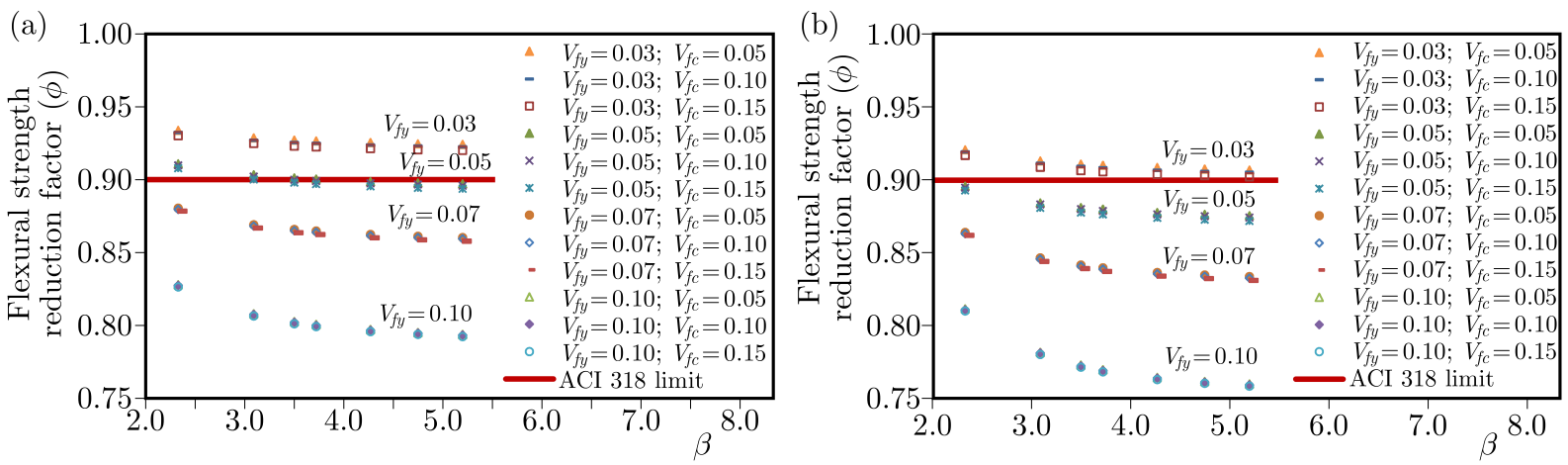

Fig. 1. Effect of variation in the $\beta$ on $\phi$; (a) NSC, (b) HSC 
Table 2. Average $\phi$ for different values of $\mathrm{COV}$ and $\beta$ values

\begin{tabular}{|c|c|c|c|c|c|c|c|c|c|}
\hline \multirow{2}{*}{ Beams } & \multirow{2}{*}{\multicolumn{2}{|c|}{$\begin{array}{l}\text { Coefficients of } \\
\text { variation }\end{array}$}} & \multicolumn{7}{|c|}{$\beta$} \\
\hline & & & 2.33 & 3.09 & 3.50 & 3.72 & 4.27 & 4.75 & 5.20 \\
\hline \multirow{12}{*}{ NSC } & \multirow{3}{*}{$V_{f_{y}}=0.03$} & $\overline{V_{f_{c}}}=0.05$ & 0.934 & 0.929 & 0.927 & $\overline{0.926}$ & 0.925 & 0.925 & 0.924 \\
\hline & & $V_{f_{c}}=0.10$ & 0.932 & 0.927 & 0.926 & 0.925 & 0.924 & 0.923 & 0.923 \\
\hline & & $V_{f_{c}}=0.15$ & 0.930 & 0.925 & 0.923 & 0.922 & 0.921 & 0.921 & 0.920 \\
\hline & \multirow{3}{*}{$V_{f_{y}}=0.05$} & $V_{f_{c}}=0.05$ & 0.911 & 0.903 & 0.901 & 0.900 & 0.899 & 0.898 & 0.897 \\
\hline & & $V_{f_{c}}=0.10$ & 0.910 & 0.902 & 0.900 & 0.899 & 0.898 & 0.897 & 0.896 \\
\hline & & $V_{f_{c}}=0.15$ & 0.908 & 0.900 & 0.898 & 0.897 & 0.895 & 0.894 & 0.894 \\
\hline & \multirow{3}{*}{$V_{f_{y}}=0.07$} & $V_{f_{c}}=0.05$ & 0.880 & 0.869 & 0.866 & 0.865 & 0.862 & 0.861 & 0.860 \\
\hline & & $V_{f_{c}}=0.10$ & 0.880 & 0.868 & 0.865 & 0.864 & 0.862 & 0.860 & 0.859 \\
\hline & & $V_{f_{c}}=0.15$ & 0.878 & 0.867 & 0.863 & 0.862 & 0.860 & 0.859 & 0.858 \\
\hline & \multirow{3}{*}{$V_{f_{y}}=0.10$} & $V_{f_{c}}=0.05$ & 0.828 & 0.808 & 0.803 & 0.801 & 0.797 & 0.795 & 0.794 \\
\hline & & $V_{f_{c}}=0.10$ & 0.827 & 0.807 & 0.802 & 0.800 & 0.797 & 0.795 & 0.793 \\
\hline & & $\frac{J_{c}}{V_{f_{c}}}=0.15$ & 0.826 & 0.806 & 0.801 & 0.799 & 0.796 & 0.794 & 0.792 \\
\hline \multirow{12}{*}{$\mathrm{HSC}$} & \multirow{3}{*}{$V_{f_{y}}=0.03$} & $V_{f_{c}}=0.05$ & 0.921 & 0.913 & 0.911 & 0.910 & 0.909 & 0.908 & 0.907 \\
\hline & & $V_{f_{c}}=0.10$ & 0.920 & 0.912 & 0.910 & 0.909 & 0.907 & 0.906 & 0.906 \\
\hline & & $V_{f_{c}}=0.15$ & 0.917 & 0.909 & 0.907 & 0.906 & 0.904 & 0.903 & 0.902 \\
\hline & \multirow{3}{*}{$V_{f_{y}}=0.05$} & $V_{f_{c}}=0.05$ & 0.896 & 0.885 & 0.881 & 0.880 & 0.878 & 0.877 & 0.876 \\
\hline & & $V_{f_{c}}=0.10$ & 0.895 & 0.883 & 0.880 & 0.879 & 0.877 & 0.875 & 0.874 \\
\hline & & $V_{f_{c}}=0.15$ & 0.893 & 0.881 & 0.878 & 0.877 & 0.874 & 0.873 & 0.872 \\
\hline & \multirow{3}{*}{$V_{f_{y}}=0.07$} & $V_{f_{c}}=0.05$ & 0.864 & 0.847 & 0.842 & 0.840 & 0.837 & 0.835 & 0.834 \\
\hline & & $V_{f_{c}}=0.10$ & 0.863 & 0.846 & 0.841 & 0.839 & 0.836 & 0.834 & 0.833 \\
\hline & & $\frac{J_{c}}{V_{f_{c}}}=0.15$ & 0.862 & 0.844 & 0.839 & 0.837 & 0.834 & 0.832 & 0.831 \\
\hline & \multirow{3}{*}{$V_{f_{y}}=0.10$} & $V_{f_{c}}=0.05$ & 0.812 & 0.782 & 0.773 & 0.770 & 0.764 & 0.762 & 0.760 \\
\hline & & $V_{f_{c}}=0.10$ & 0.811 & 0.781 & 0.772 & 0.769 & 0.764 & 0.761 & 0.759 \\
\hline & & $V_{f_{c}}=0.15$ & 0.810 & 0.780 & 0.771 & 0.768 & 0.763 & 0.760 & 0.758 \\
\hline \multirow{12}{*}{$\begin{array}{c}\mathrm{NSC} \\
+ \\
\mathrm{HSC}\end{array}$} & \multirow{3}{*}{$V_{f_{y}}=0.03$} & $V_{f_{c}}=0.05$ & 0.929 & 0.923 & 0.921 & 0.920 & 0.919 & 0.918 & 0.918 \\
\hline & & $V_{f_{c}}=0.10$ & 0.928 & 0.921 & 0.920 & 0.919 & 0.918 & 0.917 & 0.916 \\
\hline & & $V_{f_{c}}=0.15$ & 0.925 & 0.919 & 0.917 & 0.916 & 0.915 & 0.914 & 0.913 \\
\hline & \multirow{3}{*}{$V_{f_{y}}=0.05$} & $V_{f_{c}}=0.05$ & 0.905 & 0.896 & 0.894 & 0.893 & 0.891 & 0.890 & 0.889 \\
\hline & & $V_{f_{c}}=0.10$ & 0.904 & 0.895 & 0.892 & 0.891 & 0.890 & 0.889 & 0.888 \\
\hline & & $V_{f_{c}}=0.15$ & 0.902 & 0.893 & 0.890 & 0.889 & 0.887 & 0.886 & 0.885 \\
\hline & \multirow{3}{*}{$V_{f_{y}}=0.07$} & $V_{f_{c}}=0.05$ & 0.874 & 0.860 & 0.857 & 0.855 & 0.853 & 0.851 & 0.850 \\
\hline & & $V_{f_{c}}=0.10$ & 0.873 & 0.860 & 0.856 & 0.854 & 0.852 & 0.850 & 0.849 \\
\hline & & $V_{f_{c}}=0.15$ & 0.872 & 0.858 & 0.854 & 0.853 & 0.850 & 0.849 & 0.848 \\
\hline & \multirow{3}{*}{$V_{f_{y}}=0.10$} & $V_{f_{c}}=0.05$ & 0.822 & 0.798 & 0.791 & 0.789 & 0.785 & 0.782 & 0.781 \\
\hline & & $V_{f_{c}}=0.10$ & 0.821 & 0.797 & 0.791 & 0.788 & 0.784 & 0.782 & 0.780 \\
\hline & & $V_{f_{c}}=0.15$ & 0.820 & 0.796 & 0.790 & 0.787 & 0.783 & 0.781 & 0.779 \\
\hline
\end{tabular}

It is seen that $\phi$ decreases with an increase in the value of $V_{f_{y}}$. The rate of increasing in the value of $\phi$ for low values of $\beta$ is higher than that for high values of $\beta$. When $\beta$ becomes higher, the variation of $\phi$ versus $\beta$ almost becomes a smooth curve for NSC and HSC beams. For given $V_{f_{y}}$ and $\beta, \phi$ for HSC beams are found to be smaller than the one for NSC beams, so it can be inferred that $\phi$ for NSC beams is more safe than that for HSC beams. For the same $V_{f_{y}} V_{b}, V_{d}$, $V_{A_{s}}$ and $\beta$ values, it can also be said that $\phi$ values for NSC, HSC and all beams (NSC and HSC) are very close to each other for different $V_{f_{c}}$.

For some experimental beams, the effects of variations of the tensile strain in the tension reinforcement $\varepsilon_{s}$, the compressive strength of concrete $f_{c}$, the ratio of tensile strain to yield 
strain in the tension reinforcement $\varepsilon_{s} / \varepsilon_{y}$, the ratio of percentage of tension reinforcement to the percentage of balanced reinforcement $\rho / \rho_{b}$, the ratio of neutral axis depth to the effective depth $x / d$, and effective depth of the beam $d$ on the $\phi$ are plotted in Fig. 2 for $\beta=3.5, V_{f_{y}}=0.05$, $V_{f_{c}}=0.05, V_{b}=0.03, V_{d}=0.03$ and $V_{A_{s}}=0.04$.
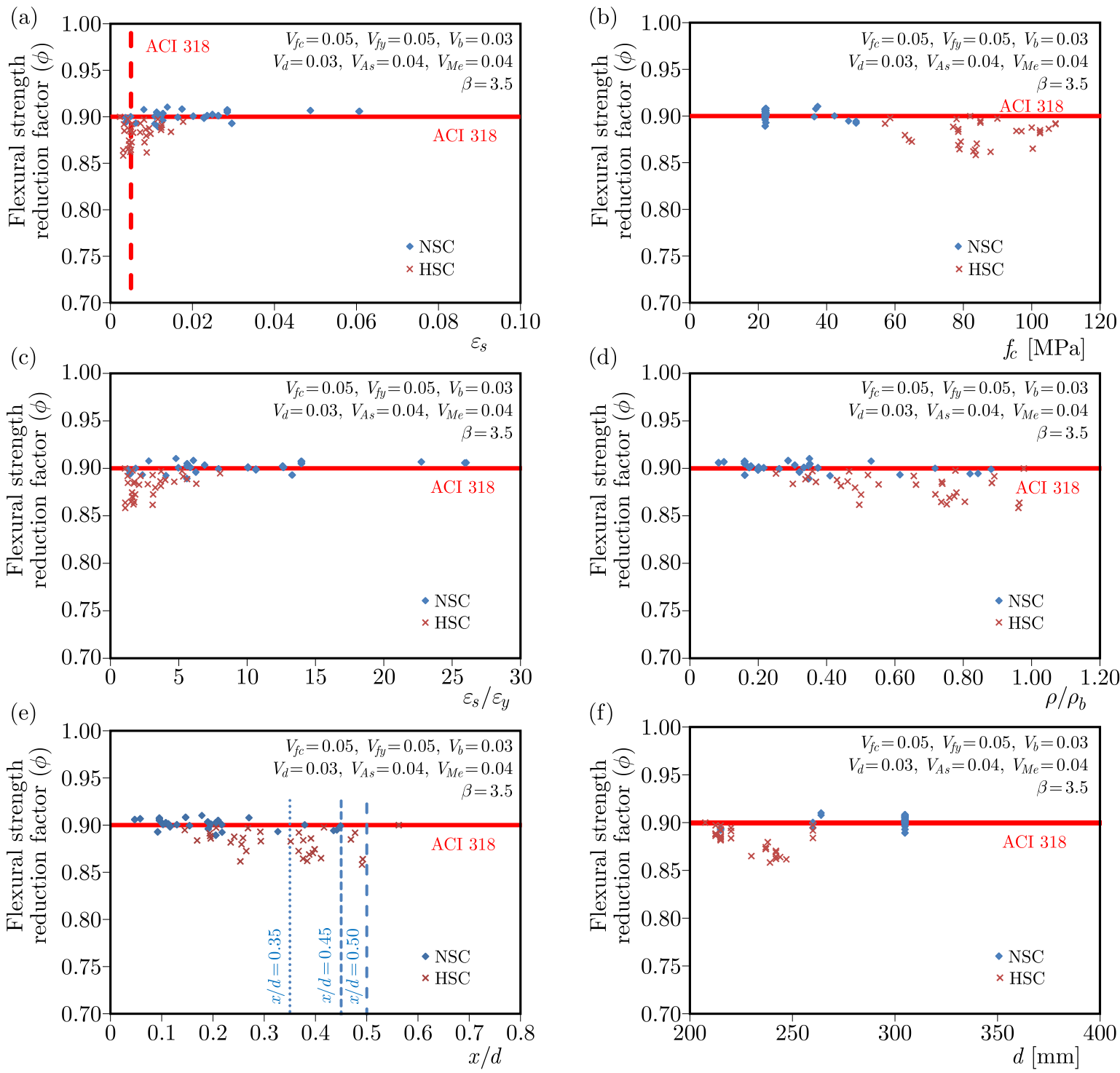

Fig. 2. Effect of variation in $\varepsilon_{s}, f_{c}, \varepsilon_{s} / \varepsilon_{y}, \rho / \rho_{b}, x / d$ and $d$ on $\phi$

The relationship of $\phi$ and $\varepsilon_{s}$ at the nominal strength for the analyzed beams is shown in Fig. 2a. According to ACI 318, if the reinforcement strain at the nominal strength is greater than $0.005, \phi$ equals to 0.90 for the desirable behavior of beam sections. $20 \%$ of the tests (4 for NSC and 12 for $\mathrm{HSC}$ of 84 tests) delivered relatively low $\varepsilon_{s}$ values $\varepsilon_{s} \leqslant 0.005$, where the corresponding strength reduction factors are mostly less than 0.90 for $\beta=3.5, V_{f_{y}}=0.05$ and $V_{f_{c}}=0.05$. It is observed that the $\phi$ factor increases with $\varepsilon_{s}$ for NSC and HSC beams. Based on the results of analyses, ACI 318 provisions are non-conservative for $\varepsilon_{s} \leqslant 0.02$. The $\phi$ factor for the existing test data yields a large scatter in the results, especially for beams with $\varepsilon_{s} \leqslant 0.02$.

Figure $2 \mathrm{~b}$ shows the $\phi-f_{c}$ for the analyzed beams. Based on the studies of the stress-strain behavior of NSC and HSC, it is shown that concrete becomes increasingly more brittle as its compressive strength is increased. Despite HSC being a more brittle material compared with NSC, the $x / d$ values of HSC sections are smaller than tkose of the NSC sections for a given $\rho$. 
Hence, HSC flexural members exhibit greater ductility owing to lower neutral axis depths (Arslan and Cihanl, 2010). Based on the results of analyses, ACI 318 provisions are non-conservative for HSC flexural beams. The $\phi$ factor for the existing test data yields a large scatter in the results, especially for HSC beams with $f_{c}>75 \mathrm{MPa}$.

The $\phi-\varepsilon_{s} / \varepsilon_{y}$ for the analyzed beams are shown in Fig. 2c. According to ACI 318, if $\varepsilon_{s}$ is at least 2.5 times the yield strain $\left(\varepsilon_{y} \cong 0.002=f_{y} / E_{s}\right)$, then the maximum value of $\phi=0.90 \mathrm{can}$ be used. $32 \%$ of the tests (10 for NSC and 17 for HSC of 84 tests) delivered relatively low $\varepsilon_{s} / \varepsilon_{y}$ values $\left(\varepsilon_{s} / \varepsilon_{y} \leqslant 5\right)$, where the corresponding strength reduction factors are mostly less than 0.90 for $\beta=3.5, V_{f_{y}}=0.05$ and $V_{f_{c}}=0.05$. It is observed that the $\phi$ factor increases with $\varepsilon_{s} / \varepsilon_{y}$ for the beams. The $\phi$ factor for the existing test data yields a large scatter in the results, especially for HSC beams with $\varepsilon_{s} / \varepsilon_{y} \leqslant 5$.

The effect of $\rho / \rho_{b}$ on $\phi$ is illustrated in Fig. 2d. The ACI 318 (1999) and previous codes limit the tension reinforcement ratio $\rho$ to no more than $75 \%$ of the ratio $\left(0.75 \rho_{b}\right)$ that would produce balanced strain conditions. The ACI 318 (2002) limits the net tensile strain $\varepsilon_{t}$ of the extreme tension steel at the nominal strength to be not less than 0.004. Meanwhile, when the net tensile strain in the extreme tension steel is sufficiently large (equal to or greater than 0.005), the section is defined as tension-controlled where ample warning of failure with excessive deflection and cracking may be expected. The effect of this limitation is to restrict $\rho$ in RC beams to about the same ratio as in editions of the code prior to $2002.69 \%$ of the tests (26 for NSC and 32 for HSC of 84 tests) delivered relatively high $\rho / \rho_{b}$ values $\left(\rho / \rho_{b} \geqslant 0.25\right)$, where the corresponding strength reduction factors are mostly less than 0.90 for $\beta=3.5, V_{f_{y}}=0.05$ and $V_{f_{c}}=0.05$. The results of the $\phi$ factor of beams with $\rho / \rho_{b}<0.25$ are limited for all the beams $(6$ for NSC of 84 tests).

Figure 2e shows the $\phi-x / d$ for the analyzed beams. The design codes BS8110, EC 2 and GBJ 11 limit the neutral axis depth $x$ to no more than a certain fraction of the effective depth $d$. It can be noted that in the design of beams, using the simplified stress block BS 8110 (1997) limits $x$ to $0.5 d$ for all concrete with $f_{c u} \leqslant 100 \mathrm{MPa}$ to ensure that the section is under-reinforced and the strain in the longitudinal reinforcement is not less than 0.0035. EC 2-1 (1992) limits the $x$ to no more than $0.45 d$ when $f_{c u}<50 \mathrm{MPa}$ or $0.35 d$ when $f_{c u} \geqslant 50 \mathrm{MPa}$. GBJ 11 (1989) requires $x$ to be smaller than $0.35 d$ for all concrete grades. The values of $\phi$ decrease significantly as $x / d$ increases from 0.2 to 0.5 . The corresponding $\phi$ of HSC beams are smaller than 0.90 for $\beta=3.5, V_{f_{y}}=0.05, V_{f_{c}}=0.05, V_{b}=0.03, V_{d}=0.03$ and $V_{A_{s}}=0.04$. Based on the results of analyses, the $\phi$ factor for $x / d>0.30$ is non-conservative for 22 flexural beams ( 5 for NSC and 17 for HSC of 84 tests). The $\phi$ factor for the existing test data yields a large scatter in the results, especially for $x / d \geqslant 0.20$.

The $\phi-d$ for the analyzed beams are shown in Fig. 2f. $6 \%$ of the NSC beam tests (3 of 52 tests) have been conducted for $d<250 \mathrm{~mm}$ and only $9 \%$ of the HSC beam tests (3 of 32 tests) have been conducted for $d \geqslant 250 \mathrm{~mm}$. The $\phi$ factor for the existing test data yields a large scatter in the results, especially for HSC beams with $d<250 \mathrm{~mm}$.

\section{Conclusion}

The change in the strength reduction factor for flexure according to the ACI 318 is investigated for different coefficients of variation and $\beta$ values. The following conclusions can be drawn from the results of this study.

- It is found that $\phi$ of 0.90 , which is a value recommended by the ACI 318 (2002) and ACI 318 (2011), corresponds to the target values of $\beta=3.5, V_{f_{y}}=0.03$ and $V_{f_{c}}=0.05$ in all analyzed beams. It is observed that this value is conservative for $\beta$ in the range from 2.33 to 5.20 for $V_{f_{y}}=0.05$ and $V_{f_{c}} \leqslant 0.15$ in NSC beams, and it can also be noted that it 
is conservative for $\beta$ in the range from 2.33 to 5.20 for $V_{f_{y}}=0.03$ and $V_{f_{c}} \leqslant 0.15$ in HSC beams.

- For the given $\beta=3.5, V_{f_{y}}=0.05, V_{f_{c}}=0.05, V_{b}=0.03, V_{d}=0.03$ and $V_{A_{s}}=0.04$, $\phi$ for the HSC beams are found to be smaller than those for the NSC beams, so it can be inferred that $\phi$ for the HSC beams is more non-conservative than that for the NSC beams.

- According to ACI 318 , if $\varepsilon_{s}$ is at least 2.5 times the yield strain $\left(\varepsilon_{y} \cong 0.002=f_{y} / E_{s}\right)$, then the maximum value of $\phi=0.90$ can be used. $32 \%$ of the tests $(10$ for NSC and 17 for HSC of 84 tests) delivered relatively low $\varepsilon_{s} / \varepsilon_{y}$ values $\left(\varepsilon_{s} / \varepsilon_{y} \leqslant 5\right)$, where the corresponding strength reduction factors are mostly less than 0.90 for $\beta=3.5, V_{f_{y}}=0.05$ and $V_{f_{c}}=0.05$. It is observed that the $\phi$ factor increases with $\varepsilon_{s} / \varepsilon_{y}$ for beams. The $\phi$ factor for the existing test data yields a large scatter in the results, especially for HSC beams with $\varepsilon_{s} / \varepsilon_{y} \leqslant 5$.

- The values of $\phi$ decrease significantly as $x / d$ increases from 0.2 to 0.5 . The corresponding $\phi$ of HSC beams are smaller than 0.90 for $\beta=3.5, V_{f_{y}}=0.05, V_{f_{c}}=0.05, V_{b}=0.03$, $V_{d}=0.03$ and $V_{A_{s}}=0.04$. Based on the results of analyses, the $\phi$ factor for $x / d>0.30$ is non-conservative for 22 flexural beams ( 5 for NSC and 17 for HSC of 84 tests). The $\phi$ factor for the existing test data yields a large scatter in the results, especially for $x / d \geqslant 0.20$.

In order to make a more reliable evaluation, the determination of the reduction factor for flexural strength of RC beams for a greater number of beams with different material and geometric properties should be realized.

\section{References}

1. AASHTO LRFD: Bridge Design Specifications, 1998, American Association of State Highway and Transportation Officials, Washington, DC

2. ACI, 1995, ACI 318M-95: Building Code Requirements for Structural Concrete and Commentary, ACI, Farmington Hills, MI, USA

3. ACI, 1999, ACI 318M-99: Building Code Requirements for Structural Concrete and Commentary, ACI, Farmington Hills, MI, USA

4. ACI, 2002, ACI 318R-02: Building Code Requirements for Structural Concrete and Commentary, ACI, Farmington Hills, MI, USA

5. ACI, 2005, ACI 318R-05: Building Code Requirements for Structural Concrete and Commentary, ACI, Farmington Hills, MI, USA

6. ACI, 2008, ACI 318R-08: Building Code Requirements for Structural Concrete and Commentary, ACI, Farmington Hills, MI, USA

7. ACI, 2011, ACI 318R-11: Building Code Requirements for Structural Concrete and Commentary, ACI, Farmington Hills, MI, USA

8. ACI, 2014, ACI 318-14: Building Code Requirements for Structural Concrete and Commentary, ACI, Farmington Hills, MI, USA

9. Akiyama M., Matsuzaki H., Dang H.T., Suzuki M., 2012, Reliability-based capacity design for reinforced concrete bridge structures, Structure and Infrastructure Engineering, Maintenance, Management, Life-Cycle Design and Performance, 8, 12, 1096-1107

10. Ang A.H.S., Tang W.H., 1984, Probability Concepts in Engineering Planning and Design. Vol. II, Decision, Risk, and Reliability, Wiley, New York, NY, USA

11. Arslan G., Alacali S., Sagiroglu A., 2016a, Assessing reduction in concrete shear strength contribution, Proceedings of the Institution of Civil Engineers, Structures and Building, 169, 4, $237-244$ 
12. Arslan G., Alacali S.N., Sagiroglu A., 2016, The investigation of the strength reduction factor in predicting the shear strength, Journal of Theoretical and Applied Mechanics, 53, 2, 371-381

13. Arslan G., Alacali S.N., Sagiroglu A., 2017, Determining the reduction factor in predicting the contribution of concrete to shear strength by using a probabilistic method, International Journal of Civil Engineering (IJCE) Transaction A: Civil Engineering, in reviewer

14. Arslan G., Cihanli E., 2010, Curvature ductility prediction of reinforced high-strength concrete beam sections, Journal of Civil Engineering and Management (JCEM), 16, 4, 462-470

15. Ashour S.A., 2000, Effect of compressive strength and tensile reinforcement ratio on flexural behavior of high-strength concrete beams, Engineering Structures, 22, 5, 413-423

16. British Standards Institution - Part 1, 1997, Structural Use of Concrete: Code of Practice for Design and Construction, BSI, London, BS 8110

17. Chinese Design Code for Highway Bridges-Beijing, 1991, People's Communication Press

18. Du J.S., Au F.T.K., 2005, Deterministic and reliability analysis of prestressed concrete bridge girders: comparison of the Chinese, Hong Kong and AASHTO LRFD Codes; Structural Safety, 27, 230-245

19. Enright, M.P., Frangopol, D.M., 1998, Probabilistic analysis of resistance degradation of reinforced concrete bridge beams under corrosion, Engineering Structures, 20, 960-971

20. Eurocode ENV 1991-3. Eurocode 1, 1994, Basis of Design and Actions on Structures. Part 3, Traffic Loads on Bridges, Final draft, August

21. European Committee for Standardisation, Design of Concrete Structures, Part 1, 1992, General Rules and Rules for Buildings, European Committee for Standardisation, Brussels, EC 2

22. Hognestad E., 1951, A study of combined bending and axial load in reinforced concrete members, Engineering Experiment Station Bulletin, 399, University of Illinois, Urbana, IL, USA

23. Hosseinnezhad A., Pourzeynali S., Razzaghi J., 2000, Aplication of first-order second moment level 2 reliability analysis of presstressed concrete bridges, 7th International Congress on Civil Engineering

24. JCSS 2000, Probabilistic model code - Part III, Joint Committee on Structural Safety

25. Johnson B., Cox K.C., 1939, High yield-point steel as tension reinforcement in beams, AC1 Journal Proceedings, 36, 1, 65-80

26. Low H.Y., HAO H., 2001, Reliability analysis of reinforced concrete slabs under explosive loading, Structural Safety, 23, 2, 157-178

27. Lu R.H., LuO Y.H., Conte J.P., 1994, Reliability evaluation of reinforced concrete beams, Structural Safety, 14, 4, 277-298

28. Minimum Design Loads for Buildings and Other Structures (SEI/ASCE 7-02), 2002, American Society of Civil Engineers, http://dx.doi.org/10.1061/9780784406243.

29. Mirza S.A., 1996, Reliability-based design of reinforced concrete columns, Structural Safety, 18. $2 / 3,179-194$

30. NAaman A.E., 2004, Limits of reinforcement in 2002 ACI code, transition, flaws, and solution, ACI Structural Journal, 101, 2, 209-218

31. National Standard of the People's Republic of China, 1989, Code for Seismic Design of Buildings, GBJ11-89 (in Chinese)

32. NowaK A.S., Collins K.R., 2000, Reliability of Structures, McGraw Hill, Boston, MA, USA

33. Nowak A.S., PARK C.H., Casas J.R., 2001, Reliability analysis of prestressed concrete bridge girders: comparison of Eurocode, Spanish Norma IAP and AASHTO LRFD, Structural Safety, 23, 331-344 
34. Nowak A.S., Szerszen M.M., 2003, Calibration of design code for buildings (ACI 318), Part 1 - Statistical models for resistance, ACI Structural Journal, 100, 3, 377-382

35. Nowak A.S., Szerszen M.M., Szwed S.A., Podhorecki P.J., 2005, Reliability-Based Calibration for Structural Concrete, Report No. UNCLE 05-03, University of Nebraska

36. Ostlund L., 1991, An estimation of T-values, [In:] Reliability of Concrete Structures. CEB Bulletin d'Information, 202, Lausanne, Switzerland

37. Pam J.H., Kwan A.K.H., Islam M.S., 2001, Flexural strength and ductility of reinforced normaland high-strength concrete beams, Structure and Buildings, 4, 381-389

38. SaAtcioglu M., 2014, Chapter 1 - Design for Flexure, Published by Albert Path on Sep. 14

39. Soares R.C., Mohammed A., Venturini W.S., Lemaire M., 2002, Reliability analysis of nonlinear reinforced concrete frames using the response surface method, Reliability Engineering and System Safety, 75, 1-16

40. Spanish Norma IAP-98, 1998, Actions in highway bridges, Road Directorate, Spanish Ministry of Public Works, Madrid

41. Structures Design Manual for Highways and Railways, 1997, Highways Department, Government of the Hong Kong Special Administrative Region, 2nd ed., with Amendment No. 1/2002, Hong Kong

42. Szerszen M.M., Szwed A., Nowak A.S., 2005, Reliability analysis for eccentrically loaded columns, ACI Structural Journal, 102, 5, 676-688

43. Val D., Bluuger F., Yankelevsky D., 1997, Reliability evaluation in nonlinear analysis of reinforced concrete structures, Structural Safety, 19, 2, 203-217

44. Wieghaus K.T., Atadero R.A., 2011, Effect of existing structure and FRP uncertainties on the reliability of FRP-based repair, Journal of Composites for Construction, 15, 4, 635-643 